\title{
Auditory screening of school children: fact or fallacy?
}

\author{
OLGA NIETUPSKA, NICK HARDING
}

In 1977 we contemplated investigating in local school children a possible correlation between intermittent loss of hearing and their scholastic performance. ${ }^{1}$ We expected to get much essential information from the school health service, which since its establishment in 1967 has worked on the principle that a school doctor should examine every child at some time during his school life to exclude or confirm the presence of handicap that might hamper his education. With progress in medical and educational science and changes in social conditions new priorities have emerged in school child health. During the past decade the importance of normal hearing as a prerequisite for a child's all-round development has been recognised, ${ }^{2}$ and consequently the school health service has introduced a programme of audiological screening as a routine procedure. For children whose loss of hearing was identified at screening procedures expert advice was made available in special units and in hospital departments.

In local primary schools the auditory screening programme is organised as follows.

Pure tone audiometry sweep test $(A S T)$ is carried out by a nonmedical, appropriately trained member of the school health service staff on all school entrants some time after their first school term and before their first school medical examination. According to a DHSS recommendation ${ }^{3}$ the ambient noise in the testing room should not exceed $30 \mathrm{~dB}$. Children who do not indicate that they hear sounds in selected frequencies at $25 \mathrm{~dB}$ of intensity "fail" the test and should be reported to the school doctor at his next visit to the school or, when necessary, to their general practitioner or to an audiology clinic or unit. It should also

\footnotetext{
King's College Hospital Medical School, London SE5 8RX

OLGA NIETUPSKA, MFCM, DPH, formerly senior lecturer and consultant, department of child health, King's College Hospital, and at present research fellow
}

Caldecot Primary School, London SE5

NICK HARDING, BCPDIPED, DIPSMS, head teacher be brought to the notice of their teacher. A senior nursing officer supervises the programme.

Hearing-for-speech test (HFST) is carried out by a school doctor on each child at the first medical examination, even if he has "passed" the pure tone audiometry sweep test. Hearing for pure tone and hearing for speech, though closely related, are not identical; the pure tone audiometry sweep test shows the degree of hearing loss, the sound frequencies affected, and the nature of the obstacle, while the hearing-for-speech test provides information on the child's comprehension of words and sentences, failure of which may or may not be due to deafness.

The school doctor thereafter has a choice of referrals to specialist units and is expected to discuss with teachers the child's hearing difficulty and its learning consequences. Clinical findings are recorded by school doctors in the child's medical file either by code $(\mathrm{O}=$ further observation; $\mathrm{R}=$ referral; $\mathrm{NT}=$ not tested, etc) or by description. The frequency and number of each test per child varies considerably, depending not so much on educational or medical as on administrative considerations, such as availability of doctors, school nurses, or session time.

This auditory screening programme offered by the school health service seemed to us reliable and adequate and indicated that the bulk of data required for our future study should be contained in the school medical record and that the hospital records would be needed in only a few cases. After some discussion with a few members of local school health service staff we concluded that before embarking on a full-scale inquiry we should carry out a short pilot study to evaluate the retrospective information in school medical records and the methods by which they were obtained. For this purpose we selected a single school in the London Borough of Lambeth, considered to be a "social priority area." Such a school, we thought, would test to the full the degree of efficiency of the school health service in achieving its objectives. ${ }^{4}$

The school has very few children from social classes I and II. Forty per cent of pupils receive free school dinners and another $20 \%$ are probably eligible. Nearly half the children do not live with both their natural parents. In an "unscientific" survey conducted within the school $40 \%$ of the parents could not name 
their family doctor. Parents in touch with the social services department knew the name of their social worker but not of their general practitioner.

\section{Pilot examination}

We decided to examine a single class of 308 -year-old children, as at this age their medical records should contain information from at least one pure tone audiometry sweep test, one hearingfor-speech test, and a routine medical examination. Like the routine school health service work our sessions were held in the school library during normal school time, with breaks for children's milk, play, and dinner. The school secretary supervised the flow of children, five a session. Parents were informed that a special medical examination was to take place and that the head teacher would notify them of relevant findings and, when necessary, would request further personal details and consent for referrals to specialists.

Clinical examination conducted jointly by a doctor (ON) and an audiotechnician (JP) consisted of pure tone audiometry (Peter's Free Field Audiometer) impedance audiometry (Limco 220 Impedance Audiometer), hearing-for-speech test (STYCAR), otoscopy, and a relevant general examination. A portable sound level meter monitored the examiner's voice and ambient noise. The only item not routinely applied in the school health service screening programme was the impedance meter.

Testing of hearing often had to be interrupted because of sudden rise in ambient noise to 70 or more $\mathrm{dB}$. The loud background noise is something a child has to cope with aimost constantly at the school. By testing the children's hearing during both the peak of din and the comparative lull (50-55 dB) we realised the extent of the mental effort made by a child with some hearing loss to discriminate the meaningful sounds from background noise. Yet experienced visitors to schools in the area have often commented on how quiet this particular primary school is compared with the others.

\section{Results}

Twelve ( $40 \%$ ) children had normal hearing. Of the remainder, four had hard wax in external meati, minor losses in pure tone audiometry, but have done well in hearing-for-speech and had normal impedance curves. All four complained of short spells of sudden deafness. " I suddenly stop hearing but I got used to it.") Seven children had significant loss on audiometry ( $30+$ $\mathrm{dB}$ in at least two conversation frequencies) and failed to hear $30 \%$ or more of the Stycar hearing-for-speech test. The impedance curves were normal. Otoscopy showed various degrees of recent otitis media; general examination showed signs of upper respiratory infection or hay fever. The remaining seven presented signs of long-standing significant hearing loss, six with flat impedance curves and unhealthy ear membranes and one, with normal otoscopy, bilateral hearing loss of $60+\mathrm{dB}$ in high frequencies, unintelligible speech, and behavioural problems. The degree of hearing loss in this last group of children undoubtedly affected their participation in class.

\section{Action}

Children with cerumen were reported to the senior nursing officer in accordance with the locally established procedure. We sympathised with the senior nursing officer's predicament for since the abolition of the so-called minor ailments clinics run by the school health service there was no set pattern of referrals nor a firmly defined responsibility as to whom school children should be referred for "de-waxing," to audiology clinic, to family doctor, or to hospital doctor. The ears of our survey children still contained hard wax at the end of the following September. Children with transient and mild hearing losses and general signs of upper respiratory infection were referred to their family doctors and also to the local audiology unit for a retest of their hearing in the autumn term.

The children with chronic hearing loss and unhealthy middle ear were referred to $\mathrm{Mr}$ Stuart Mawson, consultant ENT surgeon at King's College Hospital (a procedure previously agreed on). Chronic middle ear effusion and significant hearing loss were confirmed, and children were placed on the list for early myringotomy. Lastly the boy with sensineural deafness was referred to the local audiology unit as an urgent case. As, however, there was to be an apparently unavoidable delay of seven weeks in seeing him owing to the forthcoming school holidays, he was seen at a private hearing centre within a few days and within a fortnight was fitted with a hearing aid (free of charge). The school teacher who accompanied the boy and his mother to the hearing centre (along with his younger brother, who, incidentally, also had slight loss in high frequencies) reported to us a striking improvement in this boy's comprehension of speech and behaviour after a few weeks of using the hearing aid combined with auditory training.

\section{Summary}

Nearly three-quarters of the 8-year-olds from a single class in one school had various degrees of ear pathology and of hearing loss. Considering the extent of their social deprivation-poor and overcrowded houses, low standard of hygiene at home, inadequate diet, frequent ill-health of other family membersour findings were not totally surprising. We compared the incidence of hearing loss in our survey with the national figures obtained in the follow-up studies of the British Perinatal Mortality Survey in $1958^{5}$ (table I). Although the enormous diversity of variables in the two sets of figures undoubtedly undermine their comparability, nevertheless, the indisputable reality of schoolchildren suffering from a high incidence of hearing loss in certain socially deprived areas should not be ignored (table II).

TABLE I-Comparative incidence of hearing loss in school children

\begin{tabular}{|c|c|c|c|c|c|}
\hline & & & & $\begin{array}{l}\text { British Perinatal } \\
\text { Mortality Survey } \\
\text { follow-up } \\
\text { (7-year-olds) }\end{array}$ & $\begin{array}{c}\text { Pilot study } \\
\text { (8-year-olds) }\end{array}$ \\
\hline $\begin{array}{l}\text { Hearing loss and Db } \\
\text { Mild }(25+) \\
\text { Moderate }(35+) \\
\text { Serious }(55+) \\
\text { Severe }(75+)\end{array}$ & $\begin{array}{l}\because \\
\because \\
\cdots\end{array}$ & $\begin{array}{l}\because \\
\because \\
\cdots\end{array}$ & $\begin{array}{l}\because \\
\because \\
\therefore\end{array}$ & $\begin{array}{l}5 \% \\
0.48 \% \\
0 \cdot 17 \%\end{array}$ & $\begin{array}{c}33 \% \\
23 \% \\
3.3 \%\end{array}$ \\
\hline Total .. & $\cdots$ & $\ldots$ & $\ldots$ & $5.65 \%$ & $59 \cdot 3 \%$ \\
\hline
\end{tabular}

TABLE II-Variables in two surveys of school children examined

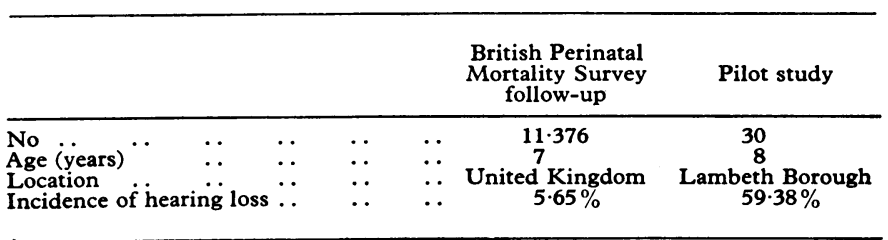

\section{Evaluation of previous auditory screening procedures}

The school medical record (IOM) of the 30 survey children contained information relevant to the auditory screening programme. The following aspects were considered: pure tone audiometry, sweep test, hearing-for-speech test, school medical examination, contribution from speech therapist and communication between the teaching staff and the school health service personnel. 
PURE TONE AUDIOMETRY SWEEP TEST

The school health service stipulates that pure tone audiometry should be carried out on all entrants and before the next school medical examination. We have confirmed that only $13(43 \%)$ of our 30 children had had an AST, and only eight of them $(27 \%)$ before the school medical examination. Thus $73 \%$ of AST results were not seen by the school medical officer. We also confirmed that, contrary to school health service directives, children who failed the test were not referred for expert testing but were retested again at school a year or two later. For example, the boy with sensineural deafness "failed" an AST test at 5 years, "passed" the next year, only to "fail" a year later, by which time he had unintelligible speech and learning and behavioural problems. Children with mild hearing loss due to otitis media were not identified at AST. Possibly the excessive background noise in the test room (see above) should be blamed for missed hearing losses: for to counteract this inconvenience the tester accepted a loss of $35 \mathrm{dBs}$ as a threshold of normal hearing, a practice not uncommon in other schools either.

We have concluded that the pure tone audiometry sweep test was unreliable and unproductive; its pseudoscientific reputation has created a false feeling of security among teaching staff.

HEARING-FOR-SPEECH TEST AND SCHOOL MEDICAL EXAMINATION

All 30 survey children attended their first medical examination at the age of 5 or 6 but only eight $(27 \%)$ had the hearing-forspeech test and $13(43 \%)$ otoscopy. At the second medical examination (for 7 year olds) 21 out of our 30 attended. Eleven $(52 \%)$ had HFST and the same number, but not necessarily the same children, had otoscopy.

Among those whom the school medical officer examined, four failed HFST and six showed otitis media of various degree. Except for one child they were not referred anywhere, neither were they followed up by the school medical officer. Altogether six out of 30 survey children have not had either test or otoscopy during their first three years of primary school. By sheer bad luck three of them had chronic middle ear effusion and significant hearing loss diagnosed at the pilot examination.

\section{Role of speech therapist}

A speech therapist when asked to see a child for diagnostic interview should have access to information from hearing assessment, paediatric examination, and psychological testing. ${ }^{6}$ Speech therapists working in specialist centres have not much difficulty in obtaining the relevant details, contrary to the speech therapists in school speech clinics, who work in comparative isolation and whose task of communicating with other members of the health care team is not always easy. For example, one boy was referred at the age of 6 to the school speech therapist by the school medical officer at the request of his teacher. A Cantonese interpreter attended the interview at the speech clinic because the child's mother knew no English. In her report the speech therapist wrote that his unintelligible speech was because Cantonese was spoken at home. The next year the child again attended the speech clinic; a different speech therapist reported that his speech disorder was due to faulty dentition and that the speech therapy should be postponed until his teeth were in good order. In this (isolated) episode the school health service speech therapist did not seek information from other professional colleagues, disregarded valuable information from the child's mother, and did not communicate with the teachers. The reports of the speech therapist, as well as the child's last (unsatisfactory) audiogram, were neatly filed in school medical records. As this child had already had the required quota of medical inspections in his primary school, school medical officers were not presented with his file. The teachers also were not aware of the content of the reports. Although the school medical records are stored on the school premises, in a cabinet to which the head teacher has keys, he himself is not allowed to read the records on the grounds of confidentiality. In the everlasting discussions at large on the sacrosanct confidentiality of medical documents no distinction is made between various types and levels of medical records. If the principle of confidentiality when applied in practice bars a head teacher from information about his pupil's hearing defect then it seems that the establishment is more concerned with the survival of a system than with the welfare of children for whom the system was created and is maintained at great cost.

\section{Co-operation between teacher and health care staff}

We completed the pilot study by asking the teachers who were in daily contact with our 30 children to comment on their learning behaviour in the classroom. Interestingly, the five children with chronic middle ear effusion had learning and behaviour problems: their progress was not steady, they did not seem to pay attention to the teacher, and did not readily join in school activities. One, a very bright boy, repeatedly asked "Pardon?" when spoken to, and the Chinese boy with high frequency deafness was, in the words of his teacher, "quite obviously deaf." Yet in each of these cases teachers who voiced their suspicion to school health service staff were "reassured" that the results of the pure tone audiometry sweep test were normal (including that of the deaf boy) or that they would be having an audiogram soon.

Rather unfortunately the valuable and truly diagnostic observations of the teachers fell, so to speak, on the deaf ears of those whose duty it was to screen children in school for hearing defects. The regrettable fence between the health care personnel and the teaching staff within this school was well illustrated by the result of the previously mentioned survey ${ }^{5}$ : only one teacher, excluding the head, could name their. school doctors, most staff would recognise the school nurse but only one could name her, and doubts were expressed by the teachers as to whether the school doctors could name or describe more than one teacher.

The Court Report" says: "If at any time during school life the pupil seems to be failing to thrive, his teacher would know that the school doctor would welcome being brought into consultation. This we regard as the most important safeguard of all-a trust and understanding between teachers and nurses and doctors based on regular discussion and shared in-service training." It says also, ". . . it is crucial that the balance between a child's health needs and his educational and social needs be understood, and effective co-operation between the three authorities and between their professional staff be established. Continuity of association as equals seems to us to be the surest method of obtaining this." ${ }^{8}$ It is clear from this survey that this is not the case here, and from our experience it is not atypical. Apparently "effective co-operation" is not only crucial but it will also cost nothing to put into practice.

\section{Conclusions}

This pilot study has led us to believe that the school health service programme of auditory screening (including school medical examinations) was ineffective and unreliable. Consequently, the data contained in school medical records should not be used as a basis of clinical assessment of children in the survey we have planned in the future. The impact of ambient noise encountered while testing children's hearing convinced us that any surveys concerned with pupils' progress versus the state of their hearing cannot be valid unless the ambient noise at school is monitored and recorded. We do not think that our findings, although not atypical, should be extrapolated to other local school health services. We believe that in order to safeguard the health of pupils the schools themselves should operate a system of continuous monitoring of their school health service's per- 
formance and should have the power to intervene. We would like to suggest that people who undertake school health work should consider deeply and sincerely their motivations to do so.

". . . It is our belief that children have special needs which they cannot articulate for themselves and society therefore has a duty to ensure that these are identified and cogently represented." 9

\section{Postscript}

This report was completed in 1978 and discussed with several members of the school health service and of teaching staff. We were pleased to know that during the following year some positive steps were taken in respect of auditory screening procedures which we all hoped would improve its performance. We have briefly reassessed the situation a year later. It seemed that the sincere effort was defeated and that the risk of a child's having an undiagnosed hearing loss that might adversely affect the quality of his future life was still in evidence. We considered that the whole system of auditory screening needs rethinking and have therefore decided to let our findings be known. We would welcome our colleagues' comments.

Nick Harding is employed by the Inner London Education Authority and states that the views expressed in this paper are not necessarily those of the authority.

We thank Professor C Eric Stroud of the department of child health, King's College Hospital, for his guidance, help, and encouragement; Mr Stuart Mawson, consultant ENT surgeon, ENT department,
King's College Hospital, for his prompt attention to the survey children; Mrs Joan Pickard, audio-technician for her so willing participation in clinical sessions; and Mrs Audrey Llewellyn (SMO schools) and her predecessor Ms Sheila Pope for their valuable information and for their understanding attitude to the aims of this study. Last, but not least, we thank the staff from Caldecot School for their co-operation and total commitment to improving the lives of the children they teach. We would also like to thank the National Medical Research Fund for supporting Olga Nietupska.

\section{References}

${ }^{1}$ Ingram TT. Intermittent hearing loss in young children. Dev Med Child Neurol 1976;18:239-41.

${ }^{2}$ Martin JAM. Hearing loss and hearing behaviour. In: The child with delayed speech. London: Heineman, 1978:87-93.

3 Department of Health and Social Security. Hospital ENT service, a design book. London: HMSO, 1974.

${ }^{4}$ Hamilton P, Ovrid HO. Comparison of hearing and socio-cultural disadvantage in relation to verbal retardation. $B r \mathcal{F}$ Audiol 1974;8: 27-30.

5 Sheriden MD. Reported incidence of hearing loss in children aged 7 years. Dev Med Child Neurol 1972;14:296-303.

${ }^{6}$ Renfrew CA. Speech therapy. Dev Med Child Neurol 1972;14:244-9.

${ }^{7}$ Committee on Child Health Services. Fit for the future. London: HMSO, 1976:150. Cmnd 6684. (Court Report P10.18.)

${ }^{8}$ Committee on Child Health Services. Fit for the future. London: HMSO, 1976:161. Cmnd 6684. (Court Report P10.58.)

9 Committee on Child Health Services. Fit for the future. London: HMSO, 1976:279. Cmnd 6684. (Court Report P16.19.)

(Accepted 23 December 1981)

\title{
Flexibility in general professional training
}

\author{
J G ROBSON
}

The royal colleges and their faculties have been anxious for some time to ensure maximum flexibility in the general professional training period, roughly the first four years after graduation. It is most desirable that young doctors should have adequate time to gain varied experience so that their career may be chosen on an informed basis and that as much as possible of that experience should be acceptable across the specialties. The Conference of Medical Royal Colleges and their Faculties in the United Kingdom requested that I report on areas of common training between the specialties so that ways and means of ensuring flexibility could be examined.

\section{Present requirements}

The colleges and their associated joint higher professional training committees have opted for formal training to (NHS) consultant standard, unlike the practice in many other countries where formal training stops some two to four years short of this point. International comparisons are not valid unless they take into account the time of achievement of the standards which we require of consultants. When such times are examined there appears to be little difference between any of the developed countries so that attempts to reduce the training period have to take our accepted system into full account. For practically all

\footnotetext{
Conference of Medical Royal Colleges and their Faculties in the United Kingdom, London W12 OHS

J G ROBSON, FRCS, FFARCS, honorary secretary
}

the specialties the colleges and joint committees have a target duration of training of eight years from qualification to consultant eligibility. The question really is whether or not the training regulations of individual colleges and faculties introduce such rigidity that they add significantly to this time.

With two exceptions, the Royal College of Radiologists and the Royal College of Pathologists, the colleges and faculties base their specialty qualifying examinations on the assumption that they will be attainable at about the fourth year after graduation. It is therefore important to know what time has been "lost" at this point if a late realisation of mistaken choice forces a change of career. A brief description of the recommended flexibility in the main specialties is revealing and I will attempt to summarise them, although reading the full regulations and consulting with the relevant college adviser is recommended to individual doctors.

The training requirements of the three colleges in medicine that award the MRCP (UK) and those for the MRCP (Ireland) are adequately non-rigid. The membership is required for all the medical specialties for which training is individually determined by the Joint Committee for Higher Training in Medicine. The examination is expected to be taken about three years after qualification, the only firm requirement being that the part II examination may be taken only after a year in an approved post practising acute medicine. Graduates who set their sights on a medical specialty can, in their first four years, have the option of at least two full years to explore other specialties in hospital or elsewhere, and it is not the wish of the colleges that they should specialise in a medical specialty at an early stage. The requirements for the Faculties of Community Medicine and Occupational Medicine make no impositions in the first 